\title{
Surface Complexation of DNA with Insoluble Monolayers. Influence of Divalent Counterions
}

\author{
D. McLoughlin, ${ }^{\dagger, \perp}$ R. Dias, ${ }^{\ddagger}$ B. Lindman, ${ }^{\S}$ M. Cardenas, ${ }^{\dagger}$ T. Nylander,${ }^{\S}$

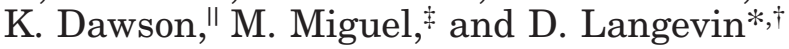

\author{
Laboratoire de Physique des Solides, Université Paris Sud, 91405 Orsay, France, \\ Physical Chemistry 1, Lund University, Chemical Centre, Box 124, SE221-00, Lund, Sweden, \\ Chemistry Department, Universidade de Coimbra, P-3004-535, Coimbra, Portugal, and \\ Department of Chemistry, University College Dublin, Dublin 4, Ireland
}

Received September 14, 2004. In Final Form: November 17, 2004

\begin{abstract}
DNA interacts with insoluble monolayers made of cationic amphiphiles as well as with monolayers of zwitterionic lipids in the presence of divalent ions. Binding to dioctadecyldimethylammonium bromide (DODAB) or distearoyl-sn-glycero-3-phosphocholine (DSPC) monolayers in the presence of calcium is accompanied by monolayer expansion. For the positively charged DODAB monolayer, this causes a decrease of surface potential, while an increase is observed for the DSPC monolayers. Binding to dipalmitoyl-snglycero-3-phosphocholine preserves most of the liquid expanded-liquid condensed coexistence region. The liquid condensed domains adopt an elongated morphology in the presence of DNA, especially in the presence of calcium. The interaction of DNA with phospholipid monolayers is ion specific: the presence of calcium leads to a stronger interaction than magnesium and barium. These results were confirmed by bulk complexation studies.
\end{abstract}

\section{Introduction}

The complexation of surfactants and polyelectrolytes of opposite electrical charges is presently the object of many studies, in view of both its fundamental interest and the large number of applications. ${ }^{1}$ Recently, there has been a particular emphasis on complex formation between cationic surfactants and DNA, ${ }^{2-8}$ due to the potential usefulness of such complexes for the transfer of genetic material to cells. ${ }^{9}$ In bulk, the binding is similar to that shown by other polyelectrolytes: one sees a high cooperativity, and above a given system-dependent surfactant concentration, there is separation into a dilute phase and a surfactant and polymer rich phase.

* Corresponding author.

† Université Paris Sud.

†niversidade de Coimbra.

$\S$ Lund University.

" University College Dublin.

${ }^{\perp}$ Permanent address: Strategic Technology Group, ICI, Wilton Centre, Redcar TS10 4RF, U.K.

(1) Goddard, E. D.; Ananthapadmanabhan, K. P. Interactions Of Surfactants with Polymers and Proteins; CRC Press: Boca Raton, FL, 1993. Kwak, J. C. T. Polymer-Surfactant Systems; Marcel Dekker: New York, 1998. Thunemann, A. F. Prog. Polym. Sci. 2002, 27, 1473. (2) Melnikov, S. M.; Sergeyev, V. G.; Yoshikawa, K. J. Am. Chem. Soc. 1995, 117, 9951-9956.

(3) Spink, C. H.; Chaires, J. B. J. Am. Chem. Soc. 1997, 119, 10920

(4) Gorelov, A. V.; Kudryashov, E. D.; Jacquier, J. C.; Mcloughlin, D M.; Dawson, K. A. Physica A 1998, 49, 216. McLoughlin, D. M.; O’Brien, McManus, J. J.; Gorelov, A. V.; Dawson, K. A. Bioseparation 2000, 9, 307-313. McLoughlin, D. M.; Gorelov, A. V.; Dawson, K. A. Prog. Colloid Polym. Sci. 2001, 118, 226.

(5) Smith, P.; Lynden-Bell, R. M.; Smith, W. Phys. Chem. Chem. Phys. 2000, 2, 1305.

(6) Buckin, V.; Morrissey, S.; Craig, E. Biophys. J. 2000, 78, 269. Craig, B. M.; Dunne, C.; Kudryashov, E. D.; Morrissey, S.; Buckin, V. Biophys. J. 2001, 80, 2057.

(7) Matulis, D.; Rouzina, I.; Bloomfield, V. A. J. Am. Chem. Soc. 2002, 124,7331

(8) Barreleiro, P. C. A.; May, R. P.; Lindman, B. Faraday Discuss. 2003, 122, 191 .

(9) Felgner, P. L.; Gadek, T. R.; Holm, M.; Roman, R.; Chan, H. W.; Wenz, M.; Northrop, J. P.; Ringold, G. M.; Danielsen, M. Proc. Natl. Acad. Sci. U.S.A. 1987, 84, 7413. Felgner, A.; Ringold, G. M. Nature 1989, 337,387 .
Polymers and surfactants also form complexes at the liquid-solid, liquid-liquid, and liquid-air interfaces. ${ }^{10}$ When soluble surfactants are used, the surfactant and polyelectrolyte composition in the adsorbed layer is controlled by the surface properties as well as by the bulk solution conditions. The use of insoluble monolayers of surfactants makes it possible to better control the charge density (fixed by the amount of spread surfactant). It is generally observed that polyelectrolyte adsorption causes monolayer expansion. ${ }^{11-15}$ Only few of these studies deal with DNA, despite the fact that in nature, surfaces are believed to play a vital role in biological processes, many of which involve DNA. Recently, DNA adsorption to hydrophobic flat surfaces and latex particles has been studied by means of ellipsometry and dynamic light scattering. ${ }^{16}$ It was found that if a DNA layer is preadsorbed and then cationic surfactant is added in the solution, the surface excess concentration significantly increases and the adsorbed layer thickness dramatically decreases. This was correlated to DNA compaction by cationic amphiphiles observed in the bulk. Recent X-ray scattering measurements showed that DNA chains order at the surface and that the resulting structure is determined by an interplay between DNA-surfactant and surfactant-surfactant interactions. ${ }^{11 \mathrm{c}}$ However, because

(10) Goddard, E. D. J. Colloid Interface Sci. 2002, 256, 228.

(11) (a) De Meijere, K.; Brezesinski, G.; Möhwald, H. Macromolecules 1997, 30, 2337. (b) Brezesinski, G.; Möhwald, H. Adv. Colloid Interface Sci. 2003, 100, 563. (c) Symietz, C.; Schneider, M.; Brezesinski, G.; Möhwald, H. Macromolecules 2004, 37, 3865.

(12) Engelking, J.; Menzel, H. Eur. Phys. J. E 2001, 5, 87. Schnitter M.; Engelking, J.; Menzel, H. Colloids Surf., A 2002, 198, 187.

(13) (a) Babak, V. G.; Vikhoreva, G. A.; Lukina, I. G. Colloids Surf., A 1997, 128, 75. (b) Babak, V. G.; Kalabina, N. N.; Vikhoreva, G. A.; Galich, E. F.; Zaitsev, S. Y.; Zubov, V. P. Mendeleev Commun. 1997, 5 202.

(14) Vagharchakian, L. S.; Hénon, S. Langmuir 2003, 19, 7989.

(15) Sastry, M.; Ramakrishnan, V.; Pattarkine, M.; Gole, A.; Ganesh, K. N. Langmuir 2000, 16, 9142. Ramakrishnan, V.; D'Costa, M.; Ganesh, K. N.; Sastry, M. Langmuir 2002, 18, 6307.

(16) Cárdenas, M.; Braem, A.; Nylander, T.; Lindman, B. Langmuir 2003, 19, 7712. Cárdenas, M.; Schillen, K; Nylander, T.; Jansson, J.; Lindman, B. Phys. Chem. Chem. Phys. 2004, 6, 1603. 
cationic lipids are toxic, mixing them with neutral lipids can reduce their toxicity. An interesting alternative is to complex zwitterionic lipids with DNA by using divalent cations, such as calcium ions. ${ }^{17,18}$ As all components are natural and nontoxic, such a system would be much better, from a cytotoxicity point of view, than conventional synthetic cationic-lipid-based delivery vectors.

In this study, we have investigated the DNA complexation with insoluble amphiphiles at the air-water interface. This includes a cationic surfactant, dioctadecyl dimethylammonium bromide (DODAB), zwitterionic lipids, distearoyl-sn-glycero-3-phosphocholine (DSPC), which gives monolayers with only a liquid condensed phase at moderate surface pressures, and dipalmitoyl-sn-glycero3-phosphocholine (DPPC), where the monolayer exhibits a transition between a liquid expanded and a liquid condensed phase. The effect of the divalent cations calcium, magnesium, and barium on the interaction between DNA and phospholipid monolayers has been studied.

\section{Materials and Methods}

DODAB was purchased from Sigma. The lipids, DSPC and DPPC, are from Avanti Polar Lipids (Alabaster, AL).The divalent salts were all analytical grade from Sigma.

A well-defined DNA segment with a length of about $80 \mathrm{~nm}$ was prepared by sonication of a calf thymus DNA (Sigma-Aldrich, D4522) solution. For this purpose, a $20 \mathrm{kHz}$ ultrasonic generator was used with a polished $6 \mathrm{~mm}$ diameter titanium probe (Sonics \& Materials, CT); $45 \mathrm{~mL}$ of a $6 \mathrm{mM}$ DNA solution was placed in a wide-mouthed conical flask. Oxygen was removed by a filtered nitrogen flow which was bubbled through for $30 \mathrm{~min}$ prior to sonication and continuously applied during sonication. The probe tip was kept a few millimeters below the surface of the solution. Sonication was carried out near $0{ }^{\circ} \mathrm{C}$ and applied continuously for $16 \mathrm{~h}$ at low power. The solution was stirred to prevent local heating and break down any convection flows induced by the sonication process. Typically the procedure gave a DNA distribution with a polydispersity of $\sim 1.5$ and a weight-average length of $81 \mathrm{~nm}$. The solution was transferred afterward to polyethylene centrifuge tubes and centrifuged for $2 \mathrm{~h}$ at $9000 \mathrm{~g}$ in order to remove titanium particles. Then it was dialyzed against the salt solution at $4{ }^{\circ} \mathrm{C}$ using a Spectropore dialysis membrane, with a MWCO of $6000-8000$. The melting curve and absorbance ratio at 260 and $280 \mathrm{~nm}\left(A_{260} / A_{280}\right)$ were recorded, and the DNA sample was split into $1 \mathrm{~mL}$ fractions and stored at $-20^{\circ} \mathrm{C}$. All experiments were carried out with $0.1 \mathrm{mg} / \mathrm{mL}$ DNA concentration.

Simultaneous measurements of the surface pressure-area isotherms and imaging of the monolayer were performed on a Nima 601 BAM trough, equipped with a Brewster angle microscope (mini BAM, Nanofilm, Germany). A filter paper plate was used for surface tension measurements; the surfactant or the lipids were spread from chloroform onto the DNA solution and left for $30 \mathrm{~min}$ to equilibrate prior to compression. The BAM comprises a light source (laser, high-power visible laser diode 30 $\mathrm{mW}$ at $688 \mathrm{~nm}$ ), a set of polarizing filters, and a light detector (a CCD camera). It had a field-of-view of $4 \times 6 \mathrm{~mm}^{2}$. The images were recorded and digitized through a Hauppauge WinTV video capture card. The temperature of the measurements was controlled at $(20 \pm 0.5)^{\circ} \mathrm{C}$.

For the simultaneous surface pressure-area isotherm and surface potential measurements, a KSV Mini trough was used equipped with a Kelvin probe (KSV, Finland) and a platinum Wilhelmy plate, which was cleaned before each measurement using an oxygen flame. The distance between the Kelvin probe and the surface was $1 \mathrm{~mm}$, and the surface potential was set to zero before spreading the surfactant or the lipid.

The bulk complexation studies were carried out as described in detail in ref $19 .{ }^{19} \mathrm{~A}$ liposome suspension was prepared by

(17) Tarahovsky, Y. S.; Khusainova, R. S.; Gorelov, A. V.; Nicolaeva, T. S.; Deev, A. A.; Dawson, K. A.; Ivanitsky, G. R. FEBS Lett. 1996, 390, 133 143 sonicating an aqueous solution of DSPC above the chain melting temperature, and then DNA was added and this solution was mixed with a stock divalent ion. A 1:5 DNA to lipid ratio was maintained in all cases. On addition of the divalent ions, a precipitate was formed containing DSPC-DNA and the divalent ion. Small-angle X-ray scattering (SAXS) measurements were performed on a Kratky compact small-angle system equipped with a position sensitive detector (OED 50M, MBraun, Austria) containing 1024 channels of width $53.0 \mu \mathrm{m}$. Cu K $\alpha$ radiation of wavelength $1.542 \AA$ was provided by a Seifert ID-300 X-ray generator operating at $50 \mathrm{kV}$ and $40 \mathrm{~mA}$. A $10 \mu \mathrm{m}$ thick Ni filter was used to remove the $\mathrm{K} \beta$ radiation, and a $1.5 \mathrm{~mm} \mathrm{~W}$ filter to protect the detector from the primary beam. The sample to detector distance was $277 \mathrm{~mm}$. To minimize the scattering from air, the camera volume was kept under vacuum during measurements. A Peltier element controlled the temperature within $25 \pm 0.1^{\circ} \mathrm{C}$. Samples were transferred into $1 \mathrm{~mm}$ glass capillaries and centrifuged to form a precipitated pellet in the bottom of the tube. The tube was then sealed with an oxygenated flame, and the samples were equilibrated at $25{ }^{\circ} \mathrm{C}$. Small-angle X-ray scattering was performed on the precipitated phases.

\section{Results}

3.1. Cationic Amphiphile-DNA Complexes. 3.1.1. DODAB. Surface pressure area $(\Pi-A)$ isotherms and surface potential area $(\Delta V-A)$ isotherms of the cationic surfactant DODAB were measured simultaneously. The isotherms were recorded for a $20 \mathrm{mM} \mathrm{NaBr}$ subphase, alone or containing $0.1 \mathrm{mg} / \mathrm{mL} \mathrm{DNA}$, and the results are shown in Figure 1. The deviation between replicates was less than $\pm 5 \%$ for the $\Pi-A$ isotherms and about $\pm 10 \%$ for the $\Delta V-A$ isotherms. For DODAB on $20 \mathrm{mM} \mathrm{NaBr}$, there is a "plateau region" in the surface pressure plot terminating around a surface area per molecule of $50 \AA^{2}$ (Figure 1a) that corresponds to the liquid expanded to liquid condensed phase transition. A corresponding plateau is also observed in the $\Delta V-A$ isotherms, which appears at area per molecule of about $50 \AA^{2}$. The general form of these curves is exactly like that in the literature (although in our case the plateaus are slightly inclined). ${ }^{20}$ Note that the literature also reports that the plateau is counterion dependent, more pronounced for $\mathrm{Cl}^{-}$, and absent for $\mathrm{I}^{-}$.

In the presence of DNA, for areas larger than $50 \AA^{2}$ the surface pressure increases, revealing complexation between DNA and the monolayer. This is analogous to what is reported in ref 11c. Upon further compression, the $\Pi-A$ isotherms with or without DNA coincide. This could indicate that DNA is squeezed out from the monolayer. However, the collapse pressure is larger in the presence of DNA, suggesting that DNA is still present and stabilizes the monolayer. The surface potential decreases, as expected from binding of negatively charged DNA to the DODAB monolayer (Figure $1 \mathrm{~b}$ ), and the $\Delta V-A$ isotherm recorded in the presence of DNA is almost parallel to the one without DNA.

Brewster angle microscopy data were obtained for the same system and show no evidence of macroscopic domain formation. However, in the plateau region, both with and without DNA, barely visible small submicron domains were observed. The compressed film is quite stiff and rigid and begins to buckle and fold at high compression, as evidenced by the appearance of film striations in the BAM images (Figure 2). Note that here the surface pressure almost compensates the bare water surface tension, whereas without DNA it only reaches values of the order of $40 \mathrm{mN} / \mathrm{m}$.

(19) McManus, J. J.; Raedler, J. O.; Dawson, K. A. J. Phys. Chem. B 2003, 107, 9869; Langmuir 2003, 19, 9630.

(20) Cavalli, A.; Dynarowicz-Latka, P.; Oliveira, O. N.; Feitosa, E. Chem. Phys. Lett. 2001, 338, 88. 

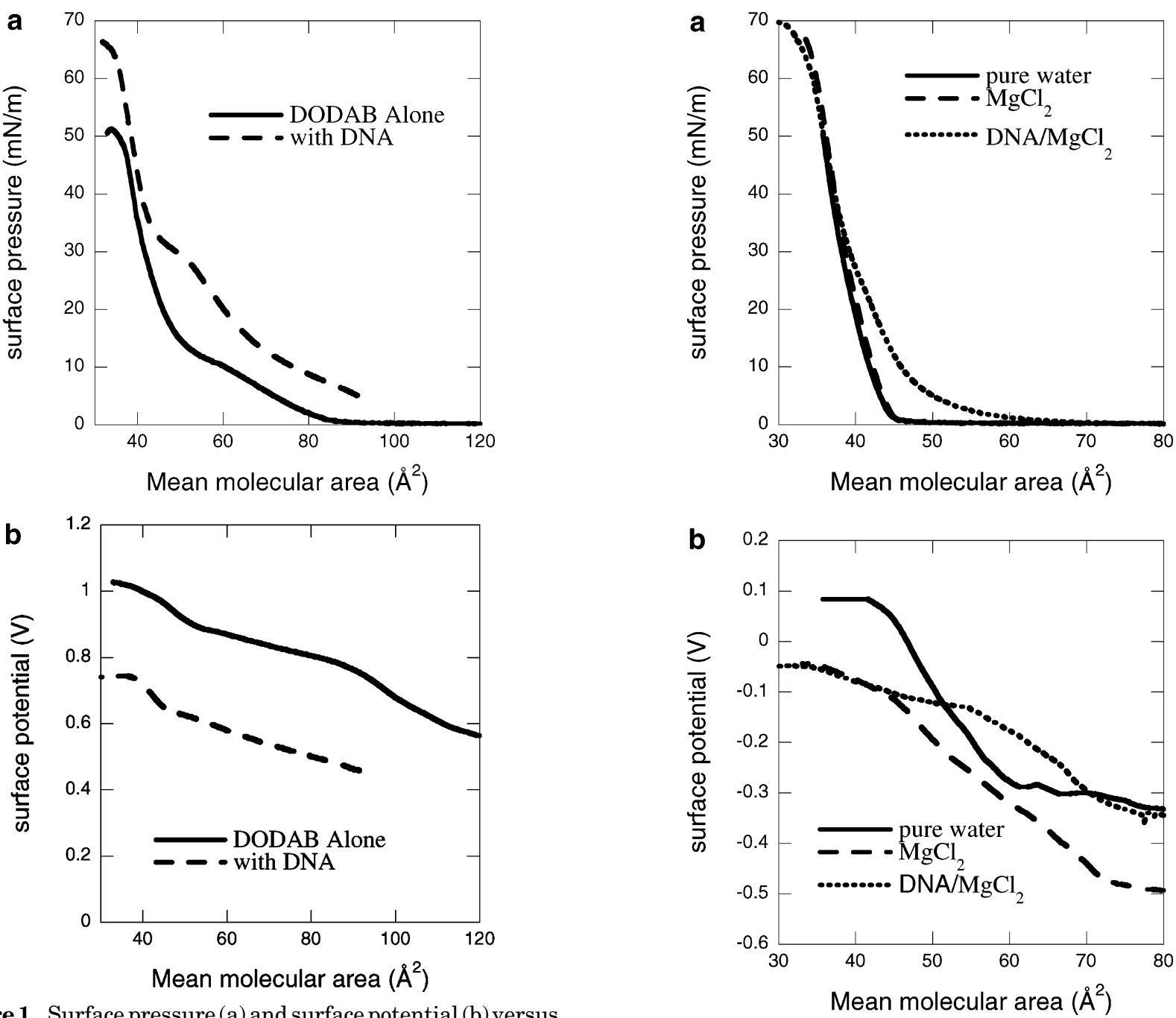

Figure 1. Surface pressure (a) and surface potential (b) versus mean molecular area for DODAB monolayers: DODAB on 20 $\mathrm{mM} \mathrm{NaBr}$ subphase (filled lines) and DODAB on $20 \mathrm{mM} \mathrm{NaBr}$ $+0.1 \mathrm{mg} / \mathrm{mL}$ DNA (broken lines).

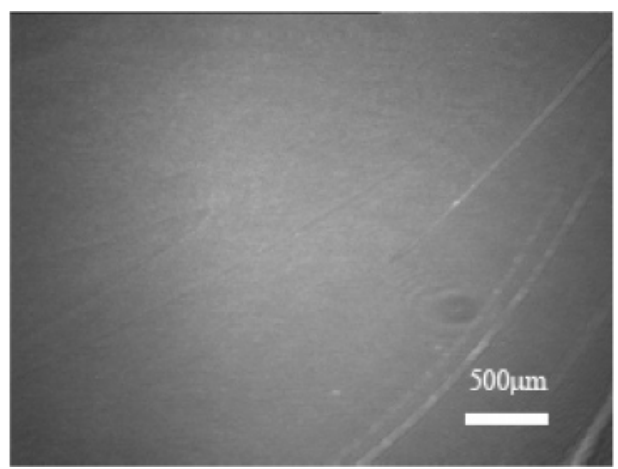

Figure 2. Brewster angle microscopy picture for DODAB on $20 \mathrm{mM} \mathrm{NaBr}+0.1 \mathrm{mg} / \mathrm{mL}$ DNA for a surface area per DODAB molecule of $40 \AA^{2}$.

\subsection{Zwitterionic Lipid-Divalent Cation-DNA} Complexes.3.2.1.DSPC-Divalent-DNASystem. The interaction between DNA and zwitterionic lipid monolayers in the presence of divalent cations was studied in the same manner as for the DODAB-DNA system. Three types of divalent ions were used: $\mathrm{Mg}^{2+}, \mathrm{Ca}^{2+}$, and $\mathrm{Ba}^{2+}$ at $5 \mathrm{mM}$ concentration. The surface potential and surface pressure curves are presented in Figures $3-5$. The $\Pi-A$ isotherm for DSPC on a water subphase is also included as a reference. The presence of divalent ions in the

Figure 3. Surface pressure (a) and surface potential (b) versus mean molecular area: DSPC on $\mathrm{H}_{2} \mathrm{O}$ subphase (filled lines) and on $5 \mathrm{mM} \mathrm{MgCl}_{2}$ subphase (broken lines) and DSPC on 5 $\mathrm{mM} \mathrm{MgCl} \mathrm{M}_{2}+0.1 \mathrm{mg} / \mathrm{mL}$ DNA subphase (dotted lines).

subphase leads to a shift of the $\Pi-A$ isotherm for DSPC to smaller areas per molecule at low surface pressures. The effect increases in the order $\mathrm{Ba}^{2+}<\mathrm{Mg}^{2+}<\mathrm{Ca}^{2+}$. We also note that the surface potential is reduced for the compressed monolayers and that for DSPC monolayers the $\Delta V-A$ isotherms in the presence and absence of added salt are not parallel.

For subphases containing DNA with $\mathrm{Mg}^{2+}$ or $\mathrm{Ca}^{2+}$, the $\Pi-A$ isotherms are shifted to higher molecular areas at surface pressures below $30 \mathrm{mN} / \mathrm{m}$. The $\Pi-A$ isotherms also feature a shoulder at around $42 \AA^{2}$. Again the magnitude of the effect was ion dependent and decreases in the order $\mathrm{Ca}^{2+}>\mathrm{Mg}^{2+}$. For $\mathrm{Ba}^{2+}$, no significant effect on the $\Pi-A$ isotherm was observed upon addition of DNA. We also note that at high surface pressures the $\Pi-A$ isotherm with and without the presence of DNA coincides. In contrast to the DODAB monolayers, no effect of the monolayer collapse pressure was observed. This trend is repeated in the surface potential data. The surface potential increases at low molecular areas in the presence of DNA. Again the magnitude of the effect was $\mathrm{Ca}^{2+}>$ $\mathrm{Mg}^{2+}>\mathrm{Ba}^{2+}$. We also note that the $\Delta V-A$ isotherms in the presence DNA are not parallel to the corresponding isotherms without DNA. This suggests that the nature or strength of the DNA-DSPC interaction in the monolayers is different from that in $\mathrm{DNA}-\mathrm{DODAB}$ monolayers. 

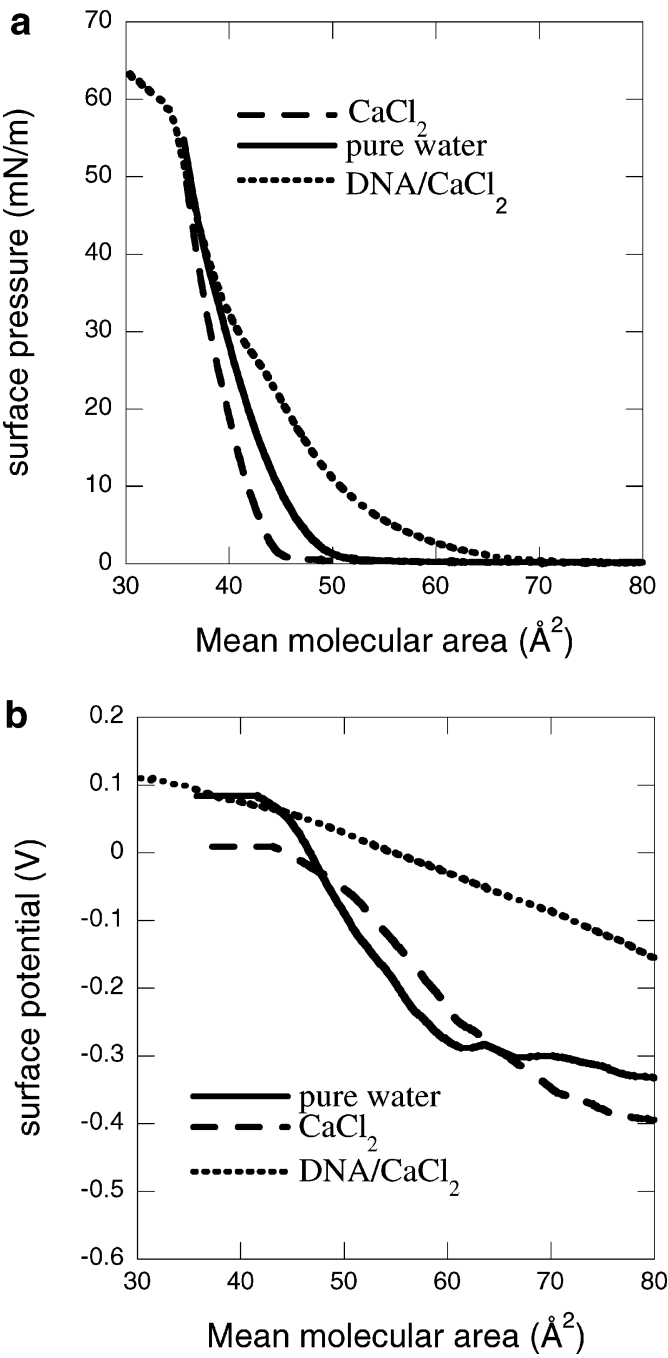

Figure 4. Surface pressure (a) and surface potential (b) versus mean molecular area: DSPC on $\mathrm{H}_{2} \mathrm{O}$ subphase (filled lines) and on $5 \mathrm{mM} \mathrm{CaCl}$ subphase (broken lines) and DSPC on 5 $\mathrm{mM} \mathrm{CaCl}{ }_{2}+0.1 \mathrm{mg} / \mathrm{mL}$ DNA subphase (dotted lines).

3.2.2. DPPC-Divalent-DNA System. The compression isotherms for DPPC monolayers on $5 \mathrm{mM}$ divalent ion solution, in the absence and presence of DNA, are shown in Figure 6. The $\Pi-A$ isotherm features a liquid expanded-liquid condensed phase transition from surface areas per molecule of 75-60 $\mathrm{A}$, for both $\mathrm{BaCl}_{2}$ and $\mathrm{CaCl}_{2}$. Addition of DNA reduces the phase transition region and shifts it toward slightly higher areas per molecule, while the surface pressure at which the phase transition occurs does not change.

We have not measured the surface potential of the DPPC monolayers, because they are inhomogeneous in most of the studied range of surface area, and the resolution of the Kelvin probe that we use is not suitable for the small size of the homogeneities (only an average surface potential would be obtained).

Concurrent Brewster angle microscopy photographs are shown in Figure 7a for DPPC on a $5 \mathrm{mM} \mathrm{CaCl}_{2}$ subphase. In the plateau region, small microscopic domains are formed. As the monolayer is compressed, the domains become more closely packed and start to merge. At high compressions, the film appears roughly homogeneous. Similar images are seen for DPPC on a $5 \mathrm{mM} \mathrm{BaCl} 2$ subphase. The domains are similar to those seen for DPPC on a pure water subphase..$^{21}$

In the presence of DNA, at large areas per molecule the situation appears to be similar to that without DNA. In
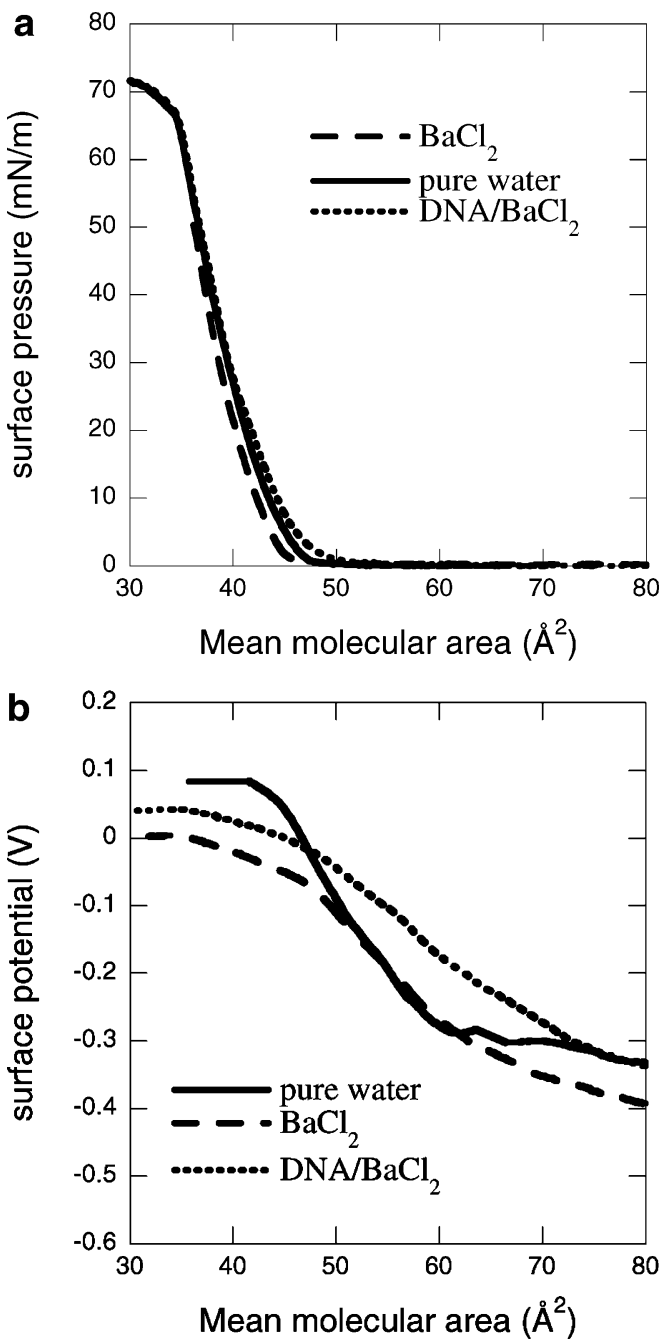

Figure 5. Surface pressure (a) and surface potential (b) versus mean molecular area: DSPC on $\mathrm{H}_{2} \mathrm{O}$ (filled lines) and $5 \mathrm{mM}$ $\mathrm{BaCl}_{2}$ subphases (broken lines) and DSPC on $5 \mathrm{mM} \mathrm{BaCl}_{2}+$ $0.1 \mathrm{mg} / \mathrm{mL}$ DNA subphase (dotted line).

the plateau region, however, the domain morphology is different. In the case of DNA with $\mathrm{CaCl}_{2}$ (Figure 7b), the domains have a serrated, elongated appearance. These domains appear to be in coexistence with the small, circular domains seen in the absence of DNA. Compression leads to striated films with some kind of aligned fibrillar structure (Figure 7c). In the case of DNA with $\mathrm{BaCl}_{2}$ (Figure 8), the domains took the appearance of dendrites. On compression, these linked together to form an extended network structure.

3.3. Bulk Studies for the DSPC-Divalent-DNA System: SAXS Results. As interesting specific counterion effects were observed in the monolayer studies, we decided to also investigate the counterion dependent effects on the complexation of DNA with liposomes composed of zwitterionic lipids. Thus, different divalent ions were added to a suspension of small unilamellar liposomes and DNA. This led to formation of a precipitated ternary complex, with mesoscopic structure. The precipitate was analyzed by SAXS for samples with DSPC, DSPC plus divalent ion, and DSPC plus divalent ion plus DNA samples. In all cases, the structure was found to be lamellar (e.g., Figure 9), but the interlayer spacing was different and smaller for $\mathrm{Ca}^{2+}$ (Table 1): the lamellar

(21) Zhao, J.; Vollhardt, D.; Brezesinski, G.; Siegel, S.; Wu, J.; Li, J B.; Miller, R. Colloids Surf., A 2000, 171, 175. 

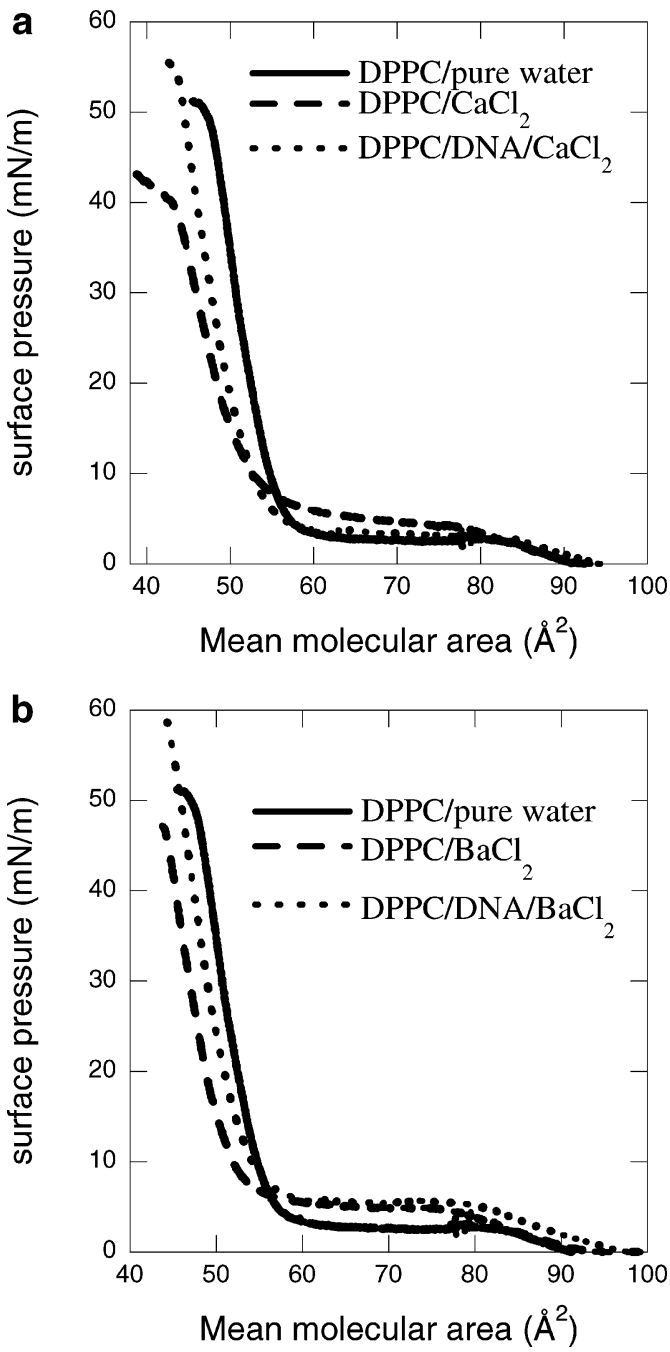

Figure 6. Surface pressure versus mean molecular area: (a) DPPC on $\mathrm{H}_{2} \mathrm{O}$ subphase (filled lines), DPPC on $5 \mathrm{mM} \mathrm{CaCl}$ subphase (broken lines), and DPPC on $5 \mathrm{mM} \mathrm{CaCl}_{2}+0.1 \mathrm{mg} /$ mL DNA subphase (dotted lines). (b) DPPC on $\mathrm{H}_{2} \mathrm{O}$ subphase (filled lines), DPPC on $5 \mathrm{mM} \mathrm{BaCl}$ subphase (broken lines), and DPPC on $5 \mathrm{mM} \mathrm{BaCl} 2+0.1 \mathrm{mg} / \mathrm{mL}$ DNA subphase (dotted lines).

Table 1. Lamellar SAXS Spacings for DSPC-Divalent Ion-DNA Systems

\begin{tabular}{lccc}
\hline & $\begin{array}{c}\text { pure } \\
\text { DSPC }(\AA)\end{array}$ & $\begin{array}{c}\text { DSPC }+ \\
\text { salt }(\AA)\end{array}$ & $\begin{array}{c}\text { DSPC }+ \\
\text { salt + DNA }(\AA)\end{array}$ \\
\hline $\mathrm{Mg}^{2+}$ & 67.5 & & 86.6 \\
$\mathrm{Ca}^{2+}$ & 67.5 & 72.5 & 84.7 \\
$\mathrm{Ba}^{2+}$ & 67.5 & 72.1 & 87.5
\end{tabular}

Table 2. Divalent Ion Mediated DNA Binding to Zwitterionic Liposomes, for Two Different Concentrations and Various Ions

\begin{tabular}{lcc}
\hline & $5 \mathrm{mM}$ salt & $20 \mathrm{mM}$ salt \\
\hline $\mathrm{Mg}^{2+}$ & $50 \%$ & $70 \%$ \\
$\mathrm{Ca}^{2+}$ & $70 \%$ & $82 \%$ \\
$\mathrm{Ba}^{2+}$ & $12 \%$ & $46 \%$
\end{tabular}

spacing is $2 \AA$ larger for $\mathrm{Mg}^{2+}$ and $3 \AA$ larger for $\mathrm{Ba}^{2+}$. A direct binding study was carried out with two divalent ion concentrations, 5 and $20 \mathrm{mM}$. The precipitates were separated out by centrifugation, and the supernatant was analyzed for DNA. Table 2 shows that DNA binding efficiency also decreases in the order $\mathrm{Ca}^{2+}>\mathrm{Mg}^{2+}>\mathrm{Ba}^{2+}$.

\section{Discussion}

First let us consider the DNA binding to cationic monolayers. The observed monolayer expansion upon polymer complexation is a classical phenomenon, observed with many different polyelectrolytes with oppositely charged surfactants or lipids. ${ }^{10}$ It has been observed in particular with DNA and methyl trioctadecylammonium bromide, ${ }^{11}$ DNA and octadecylamine monolayers, ${ }^{15}$ and DNA and methyltrioctadecylammonium bromide or DOD$\mathrm{AB}$ (as here). ${ }^{11 \mathrm{c}}$ This is because the complexation involves an exchange between surfactant or lipid counterions and polymer ions that have fixed positions along the polymer chain. As a result, the distance between surfactant hydrophobic chains adjusts to fit with the positions of these ions. ${ }^{13 \mathrm{~b}}$ In the case of DNA, the distance between ions is very small, less than $2 \AA$, but the ions are distributed along the double helix, and even if the chain is adsorbed flat, all these ions cannot face the monolayer.

The effect of polymer complexation on surface potential is less well documented. Surface potential is created by surface charges or dipoles. ${ }^{22,23}$ Because the charges are compensated by counterions, the overall effect is that of a distribution of surface dipoles. The measured potential can then be written as

$$
\Delta V=4 \pi n \mu_{\perp}+\Psi_{\mathrm{AB}}
$$

where $n=1 / A$ is the surface density of spread molecules with molecular area $A, \mu_{\perp}$ is the effective dipole moment component perpendicular to the surface, and $\Psi_{\mathrm{AB}}$ is the difference in surface potential between monolayer and water subphase. The magnitude of the effective dipole moment may vary if the distance between surface ions and counterions changes, for instance, the ionic strength in the solution varies. We have worked here in the presence of excess salt $(0.1 \mathrm{mg} / \mathrm{mL}$ DNA is equivalent to an ionic strength of $0.3 \mathrm{mM}$ ), so the addition of DNA is not expected to change the Debye length in the solution $(20 \AA$ for 20 $\mathrm{mM}$ salt, $40 \AA$ for $5 \mathrm{mM}$ ). This Debye length is also the average distance between surface ions and counterions in an ionized monolayer. The surface charge could not be too high: if the energy of a counterion becomes larger than the thermal energy, $k T$, this counterion condenses at the surface, and the surface charge saturates. ${ }^{24}$ It is not yet clear where this happens, although it seems that if the ionic strength is not too high, most ionic monolayers are fully ionized. The change in surface potential due to the addition of DNA can therefore be understood in terms of partial surface charge neutralization: the DNA charges are closer to the DODAB polar heads than their former bromide counterions. No sign of charge reversal is seen in these systems.

Let us now consider the divalent cation-zwitterionic lipid system. The shift toward smaller surface areas in the $\Pi-A$ isotherm for DSPC monolayers in the presence of divalent cations is due to the condensation of the monolayer. The divalent cation bridges neighboring molecules and thus decreases the headgroup area as discussed by McManus et al. ${ }^{19}$ At low molecular areas, the surface potential becomes more negative in agreement with a net increase in surface charge density. The effect of DNA on the $\Pi-A$ isotherm for $\mathrm{Mg}^{2+}$ and $\mathrm{Ca}^{2+}$ is similar to the effect observed with DODAB, but DNA does not seem to interact with DSPC monolayers in the presence

(22) Vogel, V.; Möbius, D. J. Colloid Interface Sci. 1988, 126, 408

(23) Kasselouri, A.; Coleman, W.; Albrecht, G.; Baszkin, A. J. Colloid Interface Sci. 1996, 180, 398.

(24) Alexander, S.; Chaikin, P. M.; Grant, P.; Morales, G. J.; Pincus, P. J. Chem. Phys. 1984, 80, 57766. 

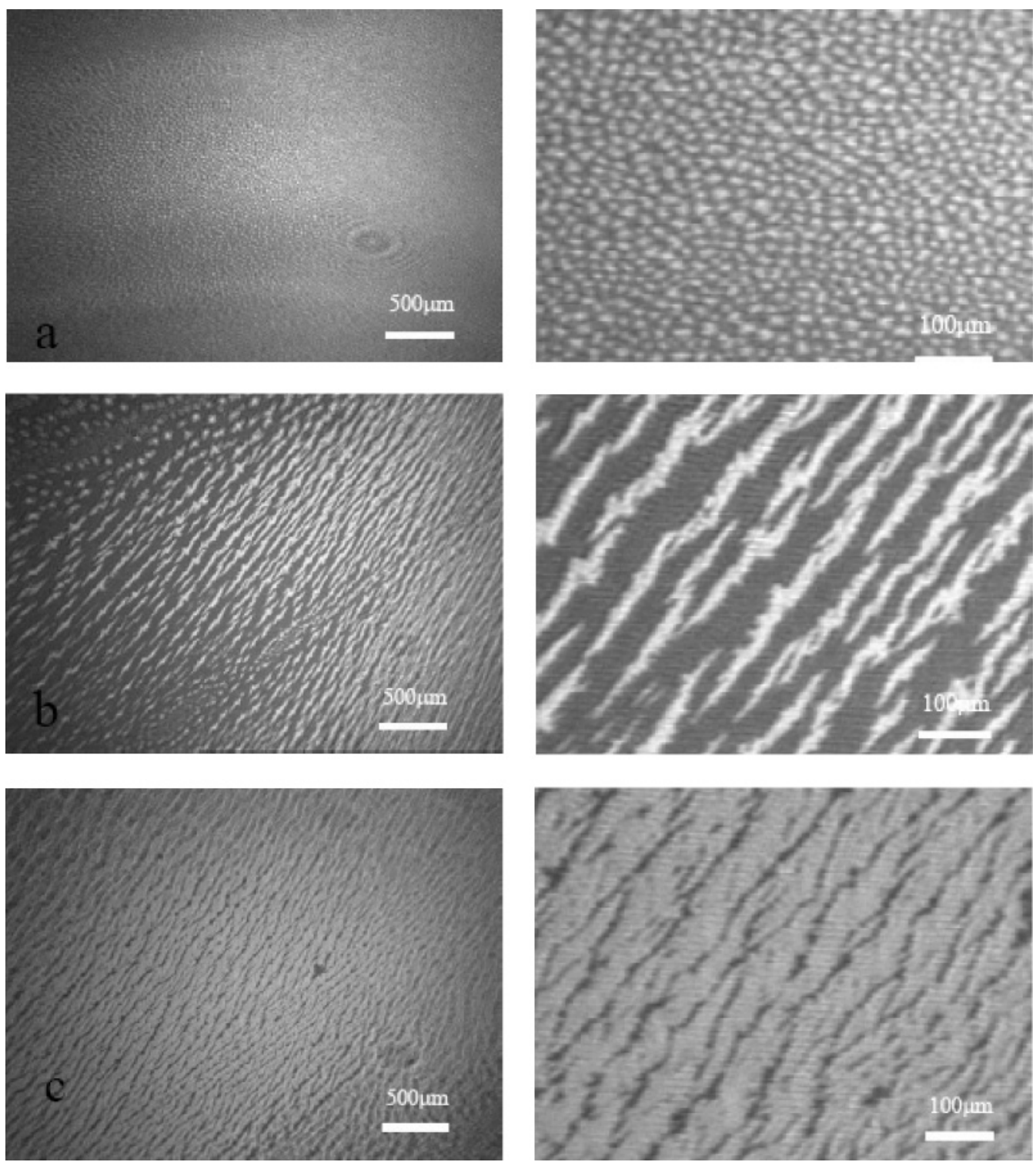

Figure 7. Brewster angle microscopy data for DPPC plus $5 \mathrm{mM} \mathrm{CaCl}_{2}$ : (a) area $60 \AA^{2}$; (b) same area, with DNA; (c) area $56 \AA^{2}$, with DNA. Wide view on left-hand side, exploded view on right-hand side.

of $\mathrm{Ba}^{2+}$. Let us note that the effect of DNA on the isotherms is more pronounced for DSPC than for DPPC (see Figures 4 and 6).

One of the most striking observations in the DPPC monolayers is the change in shape of the liquid condensed domains. McConnell and co-workers have predicted that surface domains interacting via dipolar interactions can elongate if the line tension is small enough. This occurs above a critical domain size predicted to $\mathrm{be}^{25}$

$$
R_{\mathrm{c}}=\sqrt{\frac{9 \lambda}{4}} \frac{1}{\rho}
$$

where $\lambda$ is the line tension and $\rho$ is the surface charge density; when only surface dipoles are present,

$$
R_{\mathrm{c}}=\frac{\mathrm{e}^{10 / 3} \delta}{4} \mathrm{e}^{4 \pi \epsilon \lambda / \Delta \mu^{2}}
$$

where $\delta$ is a molecular dimension, $\epsilon$ is the local dielectric constant, and $\Delta \mu$ is the difference in dipole density between

(25) Keller, D. J.; Korb, J. P.; McConnell, H. M. J. Phys. Chem. 1987 $91,6417$. the two coexisting phases. Domains of size larger than $R_{\mathrm{c}}$ are expected to be elongated. It was shown afterward that the term $\epsilon / \Delta \mu^{2}$ in the exponential could be replaced by $1 /\left(2 \epsilon_{0} \Delta V^{2}\right)$ where $\epsilon_{0}$ is the dielectric constant for vacuum and $\Delta V$ is the difference in surface potential between the coexisting phases. ${ }^{26}$ We have seen here that DNA lowers the charge density as a consequence of charge neutralization, as evidenced by a change of the surface potential toward more positive values. Because we observe elongated domains in the presence of DNA, the only rational explanation would be a simultaneous decrease of the line tension, such as the overall combination of the electrostatic interactions and of the line tension leads to a smaller $R_{\mathrm{c}}$ in the presence of DNA. The origin of this decrease in line tension is not yet clear.

When the images for the mixed DPPC-DNA monolayers in the presence of $\mathrm{Ca}^{2+}$ and $\mathrm{Ba}^{2+}$ are compared, it seems that the critical radius is larger in the second case: the surface domains are just close to the instability limit and begin to ramify. This is either because the surface charge

(26) Mann, E. K.; Hénon, S.; Langevin, D.; Meunier, J. J. Phys. II France 1992, 2, 1863. 

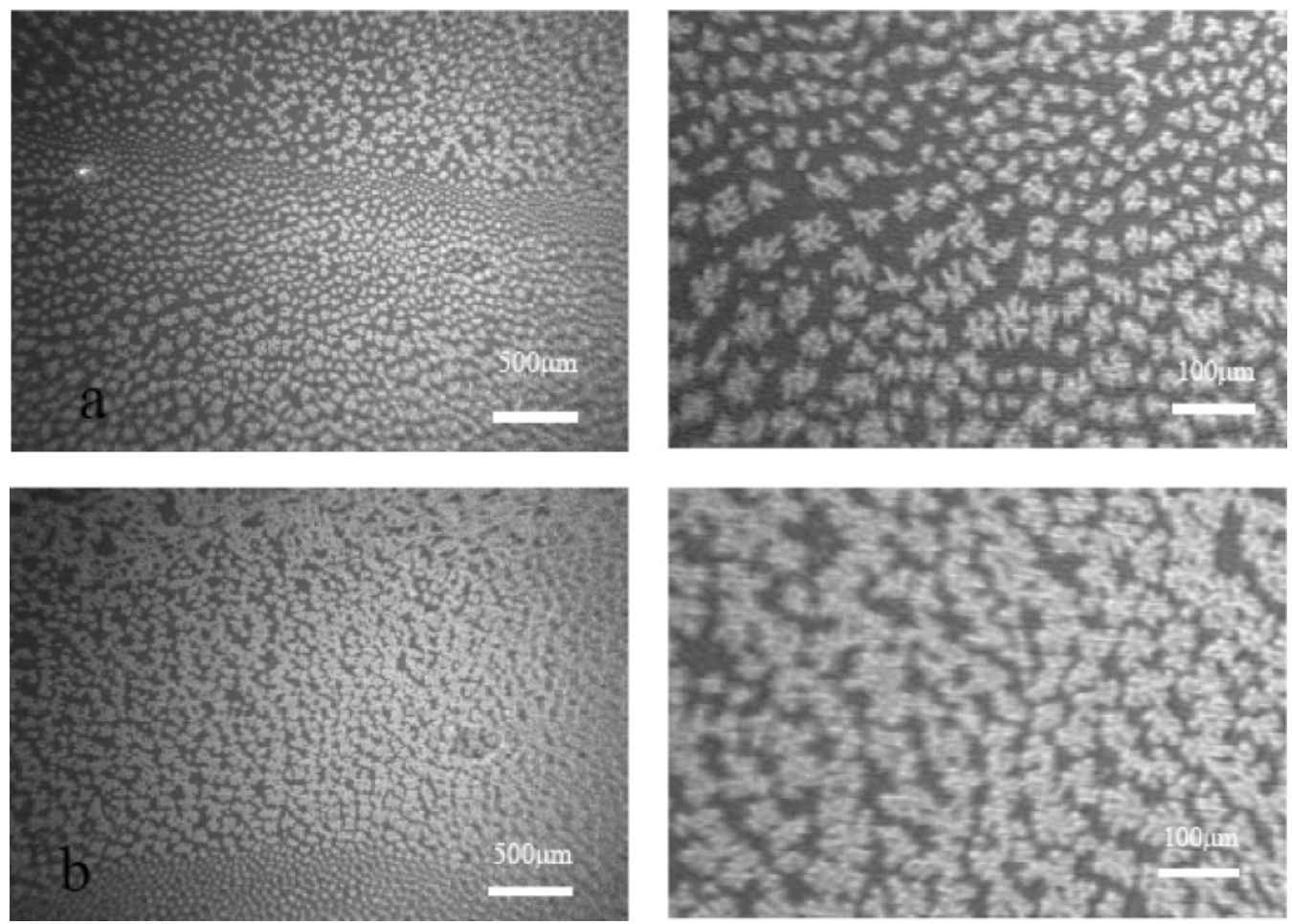

Figure 8. Brewster angle microscopy data for DPPC plus $5 \mathrm{mM} \mathrm{BaCl}$ and DNA: (a) area $60 \AA^{2}$; (b) area $57 \AA^{2}$. Wide view on left-hand side, exploded view on right-hand side.

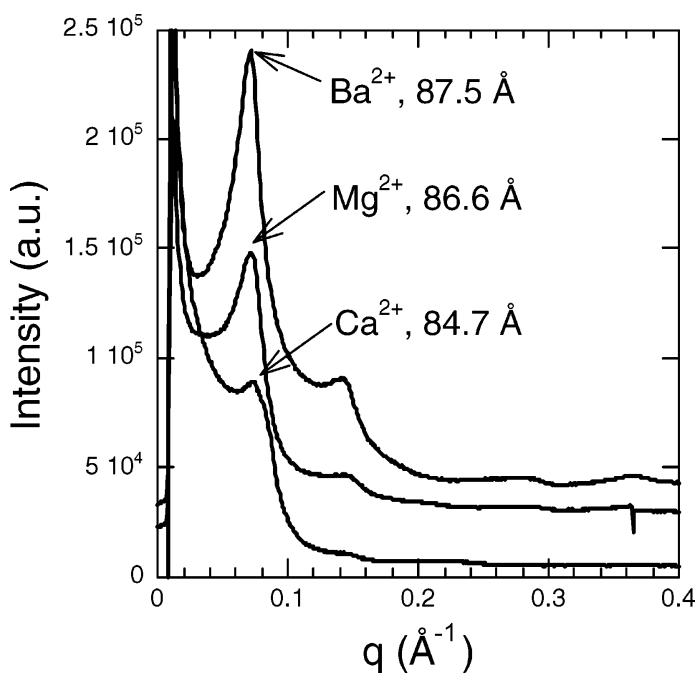

Figure 9. SAXS diffractogram of DSPC-DNA complex in the presence of (from top to bottom) $5 \mathrm{mM} \mathrm{BaCl}_{2}, 5 \mathrm{mM} \mathrm{MgCl}_{2}$, and $5 \mathrm{mM} \mathrm{CaCl} 2$. The DNA/lipid ratio was 1:5. Arrows indicate positions of first-order Bragg reflections from the lipid lamellar phase, and the corresponding interlamellar spacings are also inserted.

(or the surface potential) is less affected by DNA or because the line tension is larger.

Finally let us consider the X-ray data for the precipitated complexes. In recent detailed studies of the lamellar phases of DPPC containing calcium and DNA, it was shown that the lamellar distance increases slightly with the amount of added calcium (up to $5 \mathrm{mM}$ ) and more significantly (by about $1.5 \AA$ ) when DNA is present. ${ }^{19}$ This is very similar to what we have observed here with DSPC and calcium. The cation specific effects seen in the surface studies are mirrored here where interlamellar spacing and binding efficiency also decrease in the order $\mathrm{Ca}^{2+}>\mathrm{Mg}^{2+}>\mathrm{Ba}^{2+}$. Ion specific effects are frequent in nature. ${ }^{27}$ They are in general associated with interactions with water and are related to hydrated radius, partial molar volumes, and hydration energy (enthalpy and entropy). In the case of the three ions studied here, the properties of calcium ion are intermediate between those of magnesium and barium ions. ${ }^{28}$ Barium is the largest ion and is the one that interacts the least with water. This is in agreement with our results. However, it is difficult to explain why calcium binding is more effective than magnesium. The interactions involved here might be more specific to DNA and/or the lipid. Indeed, one sees many examples for cation specific behavior in lipid chemistry. For example, $\mathrm{Ca}^{2+}$ induces fusion of phosphatidylserine vesicles, while $\mathrm{Mg}^{2+}$ only causes aggregation. The reason for this is thought to be formation of a trans-planar complex between two opposing lipid leaflets in the case of $\mathrm{Ca}^{2+}$, while $\mathrm{Mg}^{2+}$ only forms a cis complex. Additionally, recent high-resolution structures of $\mathrm{Ca}^{2+}$ salts of B-DNA decamers have revealed various modes of $\mathrm{Ca}^{2+}$ binding to DNA other than purely electrostatic; ${ }^{29-31} \mathrm{Ca}^{2+}$ can form ionic bonds to DNA phosphate, water-mediated hydrogen bonds to phosphate oxygens, and sequence specific bonds to the DNA bases. Possibly these specific modes may account for the singular behavior of $\mathrm{Ca}^{2+}$. Interestingly, it has recently been suggested that calcium and DPPC form a new bridging unit in such a way that the lipid in effect behaves like a cationic lipid. ${ }^{31}$

\section{Conclusions}

We have shown that DNA binds to zwitterionic insoluble monolayers in the presence of divalent ions. Binding to DODAB and DSPC monolayers is accompanied by monolayer expansion and by an increase of surface potential,

(27) Kim, H. K.; Tuite, E.; Norden, B.; Ninham, B. W. Eur. Phys. J. E 2001, 4, 411 .

(28) Frank, F. Water; Plenum Press: New York, 1973; Vol. 3, pp 55 and 67 .

(29) Chiu, T. K.; Dickerson, R. E. J. Mol. Biol. 2000, 301, 915.

(30) Minasov G.; Tereshko, V.; Egli, M. J. Mol. Biol. 1999, 291, 83

(31) McManus, J. J.; Rädler, J. O.; Dawson, K. A. J. Phys. Chem. B 2003, 107, 9869 
although charge reversal was not seen. Binding to DPPC preserves most of the liquid expanded-liquid condensed coexistence region. The liquid condensed domains elongate in the presence of DNA, a feature associated with a decrease of the line tension. No precise check of the available theories is yet possible, in view of the many unknown properties of the monolayer: charge density and line tension. Binding to DNA is ion specific: calcium binds more strongly than magnesium and barium. This was confirmed by bulk complexation studies between DNA and DSPC lamellar phases. The reason for calcium's peculiarity remains to be understood. Further work is currently underway to improve the description of these mixed layers.

Acknowledgment. We are grateful to F. Livolant and her group for their help and advice during the preparation of the DNA fragments. D. McLoughlin thanks the European Community for granting him a Marie Curie postdoctoral fellowship. This work was supported in part by the EU Marie Curie Research Training Network "CIPSNAC" (Contract no. MRTN-CT-2003-504932).

LA047700S 